\title{
Del déficit a la norma: representaciones sociales sobre familias y participación escolar
}

\author{
From deficient to the norm: social representations of families \\ and school involvement
}

\section{María García Cano-Torrico /maria.garciacano@uco.es Universidad de Córdoba, España} Inmaculada Antolínez-Domínguez /iantdom@gmail.com Universidad Pablo de Olavide, España Esther Márquez-Lepe /esthermarquez@us.es Universidad de Sevilla, España

\begin{abstract}
This paper examines the social representations of families and schools with regard to their mutual involvement. The objectives are: a) to identify through the discourse of teachers, families and social agents the reasons and intentions behind involvement; and $b$ ) according to these discourse, to characterize families in relation to the way in which they fit in with legitimated relationship norms. Research was conducted in six Early Education and Primary schools in disadvantaged contexts located in Andalusia (Spain), with projects aimed at strengthening relationships between schools, families, and the community. The techniques used to produce information were individual and group interviews. The findings show a dichotomic characterisation of families: deficient vs. normalisation. Furthermore, civil associations are seen to play a role as mediators in such relationships, encouraging reflection within schools and enabling the accomplishment of more complex interpretations based on the social and cultural conditioning factors that frame these relationships.
\end{abstract}

Key words: family involvement, school, disadvantaged contexts, qualitative methodology, social representations.

Resumen: El artículo indaga en las representaciones sociales sobre familia y escuela a propósito de la participación que se da entre ambas. Los objetivos son: $a$ ) identificar a través del discurso del profesorado, familias y agentes sociales por qué y para qué se demanda participar; y b) caracterizar a las familias, según estos discursos, en relación con las normas legitimadas sobre participación. Investigamos en seis escuelas de Infantil y Primaria en contextos desfavorecidos en Andalucía (España) con proyectos dirigidos a fortalecer las relaciones entre escuela, familia y comunidad. Las técnicas de producción de información han sido entrevistas individuales y grupales. Los resultados muestran una categorización dicotómica sobre las familias: déficit vs. normalización. Además, encontramos que las asociaciones civiles ocupan un papel de mediación en dichas relaciones, impulsando la reflexividad en los centros y posibilitando interpretaciones más complejas sobre los condicionantes sociales y culturales en los que se enmarcan dichas relaciones.

Palabras clave: participación de familias, escuela, contextos desfavorecidos, investigación cualitativa, representaciones sociales. 


\section{Introducción}

Actualmente asistimos en España a un cuestionamiento generalizado sobre las prácticas y programas educativos, justificado en las elevadas tasas de abandono escolar temprano (el 12,8\% según Eurostat, 2013) o en su discreta posición en rankings internacionales que, según las pruebas PISA, sitúan al país por debajo de la media de la OECD (Ministerio de Educación, Cultura y Deporte, 2013). La materialización más evidente de este replanteamiento ha sido la aprobación de diferentes reformas escolares coincidentes con los cambios de gobierno (2002, 2006 y 2013), así como un conjunto de programas, planes y propuestas de mejora escolar que de forma reiterada aluden a la importancia de la participación de las familias en la escuela. Ésta se ha convertido en uno de los objetivos fundamentales para la mejora del éxito escolar y piedra de toque del funcionamiento del sistema educativo (Ministerio de Educación, 2012).

Existe, por tanto, en el ámbito nacional e internacional (OECD, 2012) un discurso consensuado en torno al reconocimiento de que madres y padres comprometidos fomentan actitudes positivas hacia la escuela, ayudan a mejorar el rendimiento académico de sus hijos e hijas y reduce el absentismo escolar (Boethel, 2003; Gatt et al., 2011). Y, al contrario, una baja participación de madres y padres presuponen actitudes de desinterés hacia el desarrollo socioeducativo de sus hijos e hijas (Martín et al., 2014).

Especialmente estos últimos discursos se utilizan para referirse a la relación que mantienen las clases populares, minorías étnicas o población inmigrante extranjera con la escuela, a los que se califica como distantes y/o deficitarios por su escasa participación (Theodorou, 2007; Paniagua, 2013). Asimismo, señalan como variable de los problemas escolares y la trayectoria académica del alumnado a la importancia de si las familias se acomodan o no, cómo lo hacen y cuánto al servicio de las acciones pedagógicas que los centros educativos disponen (Alonso, 2014).

Nuestra investigación ${ }^{1}$ se ubica dentro de este ámbito de estudio. Concretamente, la finalidad de este artículo es analizar, desde los enfoques teóricos del déficit, diferencia y conflicto, las representaciones sociales que se elaboran sobre la relación familia-escuela a propósito de la participación familiar. Entendemos dichas representaciones como significados recurrentes y compartidos que legitiman opiniones, valores y creencias sobre comporta-

1 Investigación financiada por el programa nacional I+D+i (EDU2010-15808) y el programa de Excelencia de la Junta de Andalucía (SEJ-6329). 
mientos, individuos o grupos (Jodelet, 2008; Ortiz, 2013). Para ello hemos planteado dos objetivos: a) identificar a través del discurso del profesorado, familias y agentes sociales que participan en las escuelas por qué y para qué se demanda dicha participación; y b) caracterizar, a partir de dichos discursos, a las familias en relación con su acomodo o no a las normas de relación legitimadas en la institución escolar.

Para lograrlos, hemos tomado dos decisiones metodológicas: en primer lugar, seleccionamos centros ubicados en contextos con fuerte desigualdad social y alta presencia de grupos minorizados. ${ }^{2} \mathrm{El}$ motivo es porque además de la importante producción científica sobre la relación entre la desigualdad de origen social del alumnado y el éxito escolar (Forquín, 1985; Fernández-Enguita, 2014), la literatura también advierte de la escasa participación familiar en estos contextos (Garreta, 2009; Paniagua, 2013). En ellos es justamente donde el discurso emitido sobre el acomodo o no a los dictados pedagógicos de participación nos permite vislumbrar cuál es el orden de responsabilidad que se les exige a las familias en el escenario escolar, así como profundizar en las atribuciones y actitudes que se les suponen.

En segundo lugar, hemos seleccionado centros que planifican de forma deliberada el cambio educativo (Fullan, 2001), desarrollando experiencias pedagógicas transformadoras que intentan potenciar las relaciones entre familias y escuela. Estudiamos precisamente los discursos del profesorado que impulsa este cambio, de familias que participan de él y de agentes sociales que colaboran con la escuela porque el consenso discursivo sobre participación que muestran (especialmente el profesorado y las familias) se revela como "legitimidades declaradas" (Martín, 1998) acerca de qué es participación y cuáles son los modos de hacerlo, convirtiéndose así en modelo o norma para los diferentes actores. Esto supone que los discursos que se producen son, como señala Van Dijk (1993), discursos hegemónicos que acceden libremente al dominio público, mientras otros son silenciados y excluidos sistemáticamente.

\section{Fundamentos teóricos}

La profusa producción científica sobre patrones de implicación parental (parental involvement) y relación (patnership) entre familias y escuelas (Swap,

2 Utilizamos el término "minorizado" y no "minoría” aludiendo a la posición en desventaja que ocupan ciertos grupos sociales en la estructura social para el acceso a recursos sociales y políticos. Ponemos, por tanto, el acento, como anota Jociles (2008), en la cualidad y no en la cantidad que representan. 
1993; Epstein, 1995; Van Voorhis et al., 2013), no nos permite hablar de participación en un único sentido. De hecho, el concepto ha sido abordado desde distintas ópticas: a) investigaciones sobre el derecho de las familias a participar en la elección del centro y sus efectos, tales como segregación escolar (Córdoba, 2011; Frakenberg, 2013); b) estudios preocupados por el análisis de las implicaciones organizativas e imperativos legales sobre la participación escolar (López, 2008; Feitó, 2014); y c) trabajos sobre representaciones y concepciones discursivas sobre participación desde la perspectiva de los docentes o de las familias, incluyendo el análisis de factores como clase social, pertenencia étnica o condición migrante del alumnado y sus familias (López-Larrosa et al., 2010; Simpkins et al., 2013).

Nuestro trabajo se ubica dentro de esta tercera línea de estudios y entendemos que es importante acercarnos a esta temática, ya que como señala Paulo Freire (1994) la participación es un elemento práctico objeto de interpretación y comprensión contextual que implica en sí mismo una "pedagogía de la comunicación”. Por ello, tal como han precisado Baquedano-López et al. (2013: 150), es pertinente caracterizar las representaciones sociales que se hacen sobre las familias en relación con la participación en las escuelas, pues muchas de las tipologías propuestas por la literatura sobre dicha relación "reflejan una visión restringida de colaboración centrada en la agenda escolar. [...] No asumen las intersecciones de raza, clase e inmigración que sí son relevantes para las experiencias de muchas familias de grupos no dominantes", siendo estas familias representadas, además, como no comprometidas con la educación de sus hijos.

Teniendo esto en cuenta distinguimos tres enfoques teóricos (déficit, diferencia y conflicto) sobre cómo se construyen las representaciones sobre dichas familias y las consecuencias de dicha construcción. El primero de ellos plantea el fracaso escolar de menores procedentes de minorías étnicas por deficiencias de tipo intelectual, pero principalmente sociocultural. Aunque esta vertiente ha sido ampliamente cuestionada, desde la perspectiva del déficit o privación cultural se explica la escasa participación de las familias debido a carencias en su entorno social y cultural, o por su incapacidad para valorar el trabajo docente, como ejemplifica Río (2010) en escuelas en zonas especialmente desfavorecidas de la ciudad de Sevilla (España). Este enfoque sigue vigente en políticas educativas nacionales e internacionales, sustentando la mayor parte de medidas legislativas de inclusión escolar de familias minorizadas en Estados Unidos de América (Banks, 2009), así

3 Traducción propia. 
como en ciertas experiencias de educación compensatoria en México y España (Antolínez, 2013).

Sin embargo, trabajos como los de Terrén y Carrasco (2007), Carrasco et al., (2009) o Franzé et al. (2010) sobre familias inmigradas contrasta con dicha imagen de desinterés. Según sus resultados, estas familias valoran positivamente la escuela como recurso socializador así como de los profesionales que trabajan en él, a pesar de que a menudo no perciban la necesidad de ajustarse a los ritmos organizativos (temporales y espaciales) que las escuelas marcan.

El segundo enfoque — de la diferencia- explica las diferencias de rendimiento del alumnado por las distancias entre el entorno escolar y el familiar. Los trabajos originarios de Ogbu (1994) mostraban que las formas de evaluar escolares ya marcan la diferencia de lenguajes y estilos cognitivos entre la población hegemónica mayoritaria y las minorizadas. La menor participación de las familias populares se explicaría por la llamada "cultura de la pobreza" y las diferencias de valores que conllevaría que las clases populares tuviesen un orden de prioridades distinto (Lewis, 1961). Investigaciones más actuales señalan la ya clásica "separación de esferas", esto es, cómo la clase trabajadora delega los asuntos escolares en la escuela, considerando que son competencia de los expertos y no de las familias (Colectivo IOE, 2010).

Ejemplos de este segundo enfoque que diferencia las competencias de la escuela y el entorno familiar son los trabajos sobre educación bilingüe con minorías hispanas en Estados Unidos (Tannen y Alatis, 2001) o de educación indígena en México (Paradise 1994; Díaz Couder, 1998; Comboni y Juárez, 2001) que diseñan programas educativos social y culturalmente pertinentes para que la escuela se adapte a la especificidad lingüística, social y cultural del contexto familiar.

Por su parte, en España, Brasil y Paraguay está teniendo gran importancia el modelo de Comunidades de Aprendizaje (CdA, en adelante) (Gatt et al., 2011; Elboj et al., 2002) para vincular comunidad y escuela. Desde dicha propuesta, la institución escolar plantea transformar su estructura y metodología para favorecer la presencia de los familiares en la institución escolar, acortando así las distancias entre la escuela y los contextos sociales y culturales de origen y favoreciendo la socialización de las familias en actitudes y comportamientos escolares.

Sin embargo, investigaciones como la de Feuerstein (2000) o Delgado y Stefancic (2012), al analizar las medidas que ponen en marcha las escuelas para favorecer la participación, señalan que el papel de las instituciones es 
bastante secundario y en todo caso sirve como reproductora precisamente de la situación de desigualdad de dichas familias minorizadas. Así, desde un tercer enfoque, el del conflicto, advierten del peligro que conlleva interpretar las desigualdades estructurales como un problema de "actitudes" que tienen las familias minorizadas, siendo así éstas las responsables últimas de las elevadas tasas de fracaso escolar entre el alumnado de clase trabajadora.

Por ello se pone el acento en los factores estructurales de constricción que evidencian una desigual distribución de recursos, entendidos en términos de capitales económicos, sociales y culturales (Bourdieu, 1980) y que implicarían redes sociales, capacidad discursiva en igualdad de condiciones con la institución escolar o los propios conocimientos escolares de las familias, factores de influencia que condicionarían el ajuste o no a los modos de participación escolar. De esta forma, como muestran algunas investigaciones (Lareau, 2000; Angus, 2009; Collet-Sabé, 2013), las prácticas de las clases más altas, al seguir estrategias cotidianas que facilitan el trabajo escolar con experiencias lúdicas y cotidianas aprovechables para éste, se convierten en pautas socialmente aceptadas, legitimadas y especialmente cercanas a las demandadas por el profesorado y el escenario pedagógico.

Por otro lado, las pautas de socialización seguidas en familias de clases populares (Price-Mitchell, 2009; Santillán y Cerletti, 2011; Martín et al., 2014) siguen estando alejadas de las demandas escolares, aunque se reconoce que se han venido transformando para adecuarse cada vez más a los requisitos de la institución escolar. Como señala Alonso (2014: 403), en estos casos el capital cultural no sólo repercute en actitudes y comportamientos sino, sobre todo, tiene el poder de "definir la norma" del comportamiento legítimo tanto social como escolar.

Estos últimos planteamientos identifican a la escuela como la principal reproductora de las diferencias con las familias y al sistema educativo como una institución al servicio de las clases hegemónicas (Ogbu, 1994; Crozier, 2001) en el que se generan discursos estigmatizadores que responsabilizan al alumnado y a sus familias por sus incapacidades y déficits de su no participación (Lott, 2001; Río, 2010; Baquedano-López et al., 2013). Nuestro trabajo avanza precisamente en esta línea de estudios, concretamente en contextos donde los perfiles de familias, en su mayoría, corresponden a colectivos pertenecientes a minorías étnicas como población gitana o inmigrante extranjera no comunitaria. 
María García Cano-Torrico, Inmaculada Antolínez-Domínguez y Esther Márquez-Lepe. Del déficit a la norma: representaciones sociales sobre familias y participación escolar

\section{Metodología}

La metodología de investigación ha sido de carácter cualitativo por considerarla la más adecuada para analizar los significados y representaciones sociales sobre relaciones familias-escuela (Ortiz, 2013).

Para la selección de la muestra de escuelas nos hemos basado en los presupuestos de la Grounded Theory. Coincidimos con Charmaz (2005) en que esta estrategia no sólo es apropiada para afrontar estudios de tipo cualitativo sino que, además, es un buen instrumento para avanzar en investigaciones sobre la justicia social, en tanto que nos permite tratar los conceptos como problemáticos y buscar sus características tal y como son vividos y comprendidos por los sujetos.

Como hemos señalado en la introducción, se han tenido en cuenta dos criterios para la selección de los centros: a) su ubicación en contextos de desigualdad y b) el desarrollo de experiencias de transformación escolar hacia una mayor comunicación/relación con las familias. En concreto, todos los centros donde hemos desarrollado nuestro trabajo se identifican como Comunidad de Aprendizaje. Esta propuesta teórico-pedagógica de orientación inclusiva (Flecha, 2009) sigue un itinerario secuenciado de fases, re-estructuraciones organizativas y estrategias metodológicas que promueven la interacción y el aprendizaje dialógico entre actores (profesorado, alumnado, familiares y otros agentes de la comunidad). Entre las actividades que desarrollan se encuentran: las tertulias dialógicas, los grupos interactivos o las comisiones de trabajo conjunto entre profesorado, alumnado y familias.

Además de estos criterios de selección hemos considerado relevante recoger cierta variabilidad, ya que nos permite maximizar o minimizar la similaridad/disimilitud de la información (Glasser y Strauss, 1967). En la Tabla I (Criterios de selección y características de las Escuelas A, B, C, D, E y F) ${ }^{4}$ mostramos la caracterización de los seis centros atendiendo a criterios como: contextos donde se ubican, alumnado minorizado, tamaño del municipio, titularidad del centro y estrategia de apertura. Nos referimos a las escuelas como A, B, C, D, E y F con el objeto de garantizar su anonimato.

El trabajo de campo se desarrolló durante los cursos 2010-2011 y 2011 2012. Las técnicas de producción de información han sido las entrevistas, tanto individuales como grupales. En total se realizaron 33 entrevistas, 15

4 Todas las tablas se encuentran en el Anexo, al final del presente documento (Nota del Editor). 
individuales y 18 grupales. En cada centro (véase Tabla II. Técnicas de producción de datos y perfil de los informantes, Tabla III. Resumen información de entrevistas individuales y Tabla IV. Resumen información de entrevistas grupales) se llevaron a cabo al menos dos entrevistas individuales y tres grupales a profesorado, familiares y a representantes de asociaciones civiles que colaboran con los centros.

En relación con el profesorado nos interesaban informantes con más de cuatro años de experiencia en el centro, así como con capacidad para diseñar e implementar actuaciones dirigidas a la participación de las familias, por ello entrevistamos a miembros del equipo directivo del centro. Respecto a las familias recogimos exclusivamente los discursos de aquellas que participaban activamente en la escuela, pues consideramos que son ellas junto al profesorado las que revelan las "legitimidades declaradas" a partir de las cuales se establecen las representaciones sociales que analizamos. Por último, en relación con las asociaciones, entrevistamos a miembros que colaboraban tanto dentro de la escuela como con las familias en los barrios, y así tuvieran una mirada más amplia sobre los procesos de exclusión y desigualdad del entorno.

Las entrevistas se dividieron en tres bloques de contenido: a) Concepciones sobre participación (cómo la perciben y actores implicados); b) Valoración de la participación (finalidad, dificultades y factores promotores); $\mathrm{y}$ c) Experiencias transformadoras sobre participación escolar (motivaciones, caracterización y valoración de las mismas).

Tanto las entrevistas individuales como las grupales fueron grabadas en audio y posteriormente transcritas de forma literal para someterlas a un proceso de codificación a través del programa de análisis cualitativo Atlas ti. v. 6.2. Dos miembros hicieron de jueces revisando toda la información codificada con el objeto de eliminar los sesgos de dicho proceso.

Utilizando el enfoque de la teoría fundamentada (Glasser y Strauss, 1967) codificamos las transcripciones empleando primero un sistema de codificación axial y abierta (Charmaz, 2005) en relación con cinco temáticas fundamentales: 1. Objetivos de la participación de las familias en la escuela; 2. Naturaleza y frecuencia de la participación de las familias en la escuela; 3. Actores implicados; 4. Factores que dificultan la participación; y 5. Factores que la facilitan. Posteriormente, con un interés interpretativo organizamos dicha información en tres bloques de contenido que son los que dan respuesta a la finalidad de este artículo: a) contextos de participación, b) familias y participación y c) agentes de mediación. 


\section{Hallazgos}

\section{Contextos de desigualdad: ausencia y desinterés}

Las motivaciones fundamentales que el profesorado expuso en nuestra investigación para promover medidas que fomentasen la participación de las familias en los centros educativos fueron dos: aumentar el rendimiento académico del alumnado y mejorar el clima de convivencia y disciplina, precisamente en unos centros cuyo contexto social y familiar es definido por la mayor parte de los discursos como problemáticos debido a su bajo nivel socioeconómico (en desempleo o dedicadas a la economía sumergida) y el escaso nivel de instrucción de las familias (sin estudios obligatorios o analfabetas): “(...) son gente con un nivel de estudios muy bajo, muy bajo, muchos problemas de droga, problemas de prostitución, mucha economía sumergida, ahora muchísimo paro..." (Entrevista individual Director Escuela E Pública, laica localizada en municipio de provincia).

De hecho, cuando en nuestras entrevistas pedimos a los equipos directivos que describiesen sus escuelas, han sido reiteradas en todas ellas las alusiones a los déficits del contexto, el alumnado y sus familias: "Tenemos una gran cantidad de alumnos que precisan refuerzo educativo, pero no solamente porque el alumnado presenta alguna discapacidad o dificultad de aprendizaje, sino por esta situación sociocultural medio bajo" (Entrevista individual Director Escuela E Pública, laica localizada en municipio de provincia).

Establecidas estas caracterizaciones -contextos en desventaja y problemática escolar-, el profesorado expuso como objetivo del cambio escolar conseguir cierta proximidad de las familias al centro. Para ello, todos los colegios estudiados optaron por procesos de transformación escolar de forma intencional con el proyecto CdA: “(...) si con todo lo que tenemos, no somos capaces de mejorar los resultados de los niños, algo más se tiene que cambiar aquí, se tiene que mover aquí, porque lo que teníamos hasta ahora no fue suficiente" (Entrevista individual Directora Escuela F Pública, laica localizada en municipio de provincia).

Ese cambio planificado pasaba, precisamente, por hacer partícipe a las familias de lo que ocurre de forma cotidiana en el centro escolar como una manera de establecer alianzas. En una entrevista grupal con maestras en referencia a los grupos interactivos 5 lo exponían del siguiente modo: "que se me-

5 Los grupos interactivos es una de las estrategias metodológicas principales para fomentar el aprendizaje dialógico en las Comunidades de Aprendizaje. Se sustenta en la división 
tan conmigo en clase, que sepan lo que son capaces de hacer sus hijos cuando están en grupo, (...) que vean, que lidien con los problemas...” (Entrevista grupal profesorado Escuela E Pública, laica localizada en municipio de provincia).

Con la presencia de las familias dentro del aula buscan: en primer lugar, hacerlos partícipes de tareas académicas y, además, promover cierta continuidad en los criterios de buena conducta entre los dictados escolares y las actitudes del ámbito familiar.

Respecto al trabajo puramente académico, el profesorado entiende que al contar con la participación de las familias aglutina esfuerzos para la instrucción de contenidos escolares:

Si estamos trabajando, por ejemplo (...) los vertebrados y tú les preguntas a los niños: venga, vamos a buscar en casa a ver si nos ayudan, ¿yo qué esperaría?, pues que todos los niños me trajeran algo, ya sea de una revista, el que puede por internet, si hay algún padre que esté un poco más preparado, algo más preparado... (Entrevista individual Jefa de estudios Escuela E Pública, laica localizada en municipio de provincia).

Esta dedicación basada en estar presente en las aulas con el rol de voluntariado, apoyar tareas académicas en casa, supervisar sus resultados, asistir a tutorías o llamadas del profesorado serviría -según el profesorado- de refuerzo a los saberes impartidos en el aula, siendo un bien instrumental al servicio del aprendizaje escolar.

Desde esta perspectiva, cumplir con lo académico, también lleva aparejado todo un entramado de actitudes y comportamientos que se consideran adecuados y repercuten -entiende el profesorado- de forma directa en el éxito académico del alumnado. Nos referimos al cumplimiento de ciertos hábitos de cuidado de materiales y vestimenta, higiene, decoro, etc., cuyo ejercicio afecta a lo que se hace en el escenario escolar pero, fundamentalmente, a lo que se hace y cómo en el espacio familiar.

Ejemplo de ello es la referencia que nos hacía la directora del centro religioso estudiado sobre las familias de etnia gitana al pedirle que describiera el colegio: “ ¿Te has dado cuenta cómo vienen las madres por las mañanas a traer a sus hijos?, algunas vienen con sus batas de recién levantadas para cuando lleguen a casa volverse a acostar" (Entrevista individual Directora Escuela B Concertada, religiosa, municipio de provincia).

del grupo-clase en subgrupos heterogéneos de 4 o 5 estudiantes que serán tutorizados por un/a adulto/a voluntario/a, el cual no ejerce de docente sino de guía en la realización de la actividad. 
La selección de dichos aspectos al describir a las familias denota la importancia que el profesorado otorga a los hábitos seguidos por éstas y cómo, en cierta medida, les sirve de justificación para explicar precisamente el desinterés y la desatención que el profesorado encuentra en el alumnado -en sus hijos e hijas- hacia lo escolar. Aspectos que sirven para definir por qué y para qué proyectan fomentar la participación de las familias en el centro así como para caracterizarlas, tomando como referente su distancia respecto los dictados de la institución.

Ha sido en tales casos, cuando la representación social que se hace sobre las familias por parte del profesorado se dibuja tan distante y divergente a la institución que deriva en posturas enfrentadas o, al menos, en la consideración de las distancias como insalvables. Ejemplo de ello es el uso que se hace de un lenguaje bélico para explicar la participación de las familias en el centro escolar con expresiones como "luchar juntos", "a quién nos enfrentamos", "la batalla educativa": "Yo creo que una ventaja ¿no?, el conocer a quién te vas a enfrentar es una ventaja..." (Entrevista grupal profesorado Escuela E Pública, laica localizada en municipio de provincia).

El establecimiento de este campo de lucha sirve al profesorado de las escuelas de nuestro estudio, por un lado, para identificar cuáles son las reglas que definen qué es lo normal y adecuado, esto es, imitar de alguna forma la labor de los maestros en casa (explicar, ampliar contenidos y/o evaluar) y, además, fomentar una actitud de motivación y aceptación hacia el trabajo escolar. Como señala Alonso (2014), éstas son prácticas de socialización comunes entre las clases dominantes con mayor capital cultural, reproduciéndose a través de lo que se hace en la escuela y en lo que en ella se promueve.

De forma recurrente estos argumentos se han evidenciado en nuestro estudio especialmente en las referencias a familias no dominantes de etnia gitana y de origen extranjero. Para el caso concreto de las primeras, ha sido reiterativa la alusión y, por tanto su caracterización, de acuerdo a su falta de expectativas académicas y desconfianza hacia el sistema de educación formal:

(...) es que no hay implicación, ellos no tienen valores, (...), ellos la educación no tienen valor, ellos tienen a los chiquillos aquí porque tienen que tenerlos aquí, si tuvieran valor de la educación como tenemos otras personas, pues las cosas cambiarían; porque claro, ellos no tienen en la escala de valores que la educación es la clave del futuro, no tienen esa..., sí, nosotros sí lo tenemos, nosotros a nivel..., unos más y otros menos, según el nivel cultural que tengamos..." (Entrevista individual Jefe de estudios Escuela B Concertada, religiosa, municipio de provincia).

En estos casos, la diferencia cultural sirve para explicar su posición de déficit desde una visión que responsabiliza a los sujetos (y su grupo de per- 
tenencia) de la distancia que mantienen en las prácticas de socialización y educación de sus hijos con la normalidad, es decir, con la escuela (Río, 2010).

Para el caso de las familias inmigrantes, sobre todo en aquellos centros donde su presencia no es muy significativa (como es el caso de la escuela D cercana al 5\%), el profesorado alude de manera generalista a cómo su forma de vida y las supuestas condiciones laborales en las que se desenvuelven explican su falta de apoyo e interés por la promoción de sus hijos e hijas:

Maestra 3: Yo tengo una rumanilla [procedente de Rumanía] bien adaptada, lo que pasa es que los padres se van por ahí a trabajar, se queda con un hermano, que el hermano es mayor de edad, pero está viviendo en unas condiciones que no..., yo no puedo pedirle a esa niña más de lo que le pido, porque es que yo llamo a su hermano, y yo no veo, no veo continuidad en el proceso, no veo interés... (Entrevista grupal profesorado Escuela D Pública, laica, localizada en capital de provincia).

Por tanto, se trata de un discurso cercano al enfoque del déficit que cuestiona y responsabiliza los modos de hacer en la escena familiar, dados sus déficits y privación social y cultural en los que se desenvuelven (Antolínez, 2013).

Si bien este es el discurso que hemos encontrado en la mayor parte del profesorado de los centros estudiados, hemos identificado un caso particular (Escuela C Pública, laica, localizada en capital de provincia) donde no se dan estos presupuestos. El discurso de este profesorado procura alejarse de posturas confrontadas, apostando de forma constante por el diálogo y la apertura de espacios, rompiendo fronteras que separen escenarios o tareas. Así lo expresaba una profesora al explicar el objetivo de su proyecto educativo:

Que las puertas del colegio están abiertas, que las familias vengan aquí como si fuera su segunda casa y nosotros también ofrecer a la familia, al barrio todo lo que hacemos en el cole, salimos en carnaval, salimos a hacer aulas abiertas fuera, nos metemos en las plazas de aquí del barrio a limpiarlas, a pintarlas, entonces era un objetivo fundamental en los orígenes del proyecto (Entrevista individual Jefa de estudios, Escuela C).

Y así lo señalaba un padre de familia al hablar sobre qué significa para ellas la apertura por parte del centro escolar: "relaciones es dejar que participe en la clase con los niños, si quieres hacer teatro los profesores se prestan para que hagas teatro,..." (Entrevista grupal familias, Escuela C). Si bien aún no tenemos las claves para identificar los factores que propician esta diferenciación respecto a otros centros, sospechamos que los procesos de interrelación constantes con las asociaciones sociales, como describiremos más adelante, están provocando miradas de reconocimiento entre los actores escolares más cercanas al enfoque del conflicto que al del déficit o la diferencia. 
María García Cano-Torrico, Inmaculada Antolínez-Domínguez y Esther Márquez-Lepe. Del déficit a la norma: representaciones sociales sobre familias y participación escolar

Respuestas aliadas y respuestas confrontadas con la agenda escolar por parte de las familias

Las concepciones que las familias tienen sobre la participación en los centros educativos estudiados están en buena medida en consonancia con lo manifestado por parte del profesorado. De hecho, las razones a las que aluden aquellas familias que están presentes de forma cotidiana en los centros, asistiendo como voluntarias a las aulas o formando parte de Comisiones de organización, ${ }^{6}$ se refieren a las difíciles condiciones socioeconómicas en las que viven y, por tanto, a la necesidad de apoyar el trabajo del profesorado para mejorar la posición social de sus hijos respecto a la suya propia.

Su posicionamiento sobre qué significa participar es bastante coincidente con el del profesorado, por lo que no participar es interpretado por estas familias como no tener un compromiso hacia la educación de sus hijos e hijas. Por ello, las esperanzas puestas en los centros educativos son equiparables a los deseos de mejora y ascenso social, conscientes de las condiciones de marginalidad y desigualdad en las que se encuentran. De forma explícita, las familias que pasan a vincularse a la esfera escolar buscan acortar distancias y acomodarse a los requerimientos escolares como forma de promoción social (Elboj et al., 2002). Ante la pregunta de qué esperan de la escuela las madres planteaban:

Madre 1: Lo que no hemos podido tener nosotras (...) Eso, una educación, un futuro, una economía... Hombre, no pedimos que sean ministros (...). Algo que no "habemos" podido tener nosotras, que es una estabilidad de vida, y que sean algo más que un simple parado, o un simple obrero en el paro en un barrio marginal, que tengan una esperanza de algo que nosotras no hemos tenido. Pero no tan sólo para nuestros niños sino para todos los niños del barrio, que para eso estamos aquí, hay muchos niños (Entrevista grupal familias, Escuela D Pública, laica, localizada en capital de provincia).

Identificamos, en el discurso de las familias, un reconocimiento del esfuerzo realizado por parte del profesorado y la dirección de los colegios por impulsar y mantener las actividades del proyecto de $\mathrm{CdA}$, mostrando su disponibilidad para participar en todo aquello que sea propuesto desde la escuela, discursos que se relacionan con el enfoque de la diferencia referido anteriormente (Tannen y Alatis, 2001). Pero además, este discurso muestra un apoyo incondicional a los objetivos y medidas establecidas por la insti-

6 Las Comisiones en el proyecto de CdA son conformadas por familiares, profesorado, alumnado y voluntariado que se reúne y toma decisiones sobre un tema de importancia para el centro, como pueden ser infraestructuras del centro o la organización de celebraciones. 
tución, por eso lo calificamos como escolar-céntrico. Así, madres que están muy implicadas en las actividades del colegio, cuando les preguntamos en qué estaban participando exactamente nos respondían: “(...) es que nosotros ayudamos en lo que los profesores nos piden. (...) Hacemos de todo, todo lo que se pueda, claro" (Entrevista grupal familia, Escuela A Pública, laica, localizada en una capital de provincia).

Dicha manifestación "en lo que los profesores nos piden" y su aclaración, "todo lo que se pueda, claro" evidencia, desde una perspectiva de la diferencia, una separación clara de esferas de actuación así como de roles y encargos que cada uno tiene en la labor educativa (Colectivo IOÉ, 2010). Reconocen el papel del profesorado como expertos que juegan en su terreno, el centro educativo, al que acuden para apoyar pero no para decidir, por lo que las diferencias no se desdibujan, sino se suplen con su acomodo a lo demandado por la escuela (Santillán y Cerletti, 2011).

Estas familias próximas a la institución, y que caracterizamos según la interpretación que hacemos del discurso del profesorado como normalizadas, tal como señalamos anteriormente, presentan un discurso muy crítico con las familias que no participan, a las que les reprochan asuntos como "dejan aparcados a sus hijos en la escuela” (Entrevista grupal familia, Escuela F Pública, laica, localizada en municipio provincia) o "no quieren saber nada" (Entrevista grupal familia, Escuela D Pública, laica, localizada en capital de provincia).

$\mathrm{Al}$ igual que en el caso del profesorado, las culpabilizan y caracterizan por su conformismo, falta de expectativas y apoyo a sus hijos o por su desafección hacia la escuela. Elementos afines al enfoque del déficit que responsabilizan a las familias de sus carencias y ausencias. En ningún momento hemos encontrado que este discurso sea crítico con las estrategias seguidas por la institución escolar para conseguir una mayor implicación parental y sólo en algunas ocasiones, como ocurre con el caso del profesorado, dicha ausencia se justifica por parte de las familias por el modo de vida o las condiciones laborales de ciertos grupos, especialmente familias gitanas o extranjeras, explicando la no presencia de éstas dentro del aula porque no saben cómo hacerlo, de nuevo, por sus carencias.

Así, algunas madres, en las entrevistas grupales, explicaban cómo muchas mujeres acuden a los centros para conseguir recursos de primera necesidad ${ }^{7}$ pero no para participar en las actividades académicas que el centro organiza:

7 En todos los centros estudiados se organizaban de forma voluntaria recogida y donación de productos de este tipo a instancia del profesorado y en el que participaban también, en la recaudación y reparto, familias y voluntariado de asociaciones civiles de los barrios. 
Madre 1: (...) es que [nombre de una de las madres de alumnado] que es rumana no puede venir porque está todo el día pidiendo en la calle.

Madre 3: Hay muchas madres que no vienen porque son gitanas y no saben ni leer ni escribir.

Madre 4: Es que aquí hay muchos que vienen de Marruecos y sus hijos son los que le enseñan el español, entonces ¿cómo van a estar en las clases? (Entrevista grupal familias, Escuela B, Concertada, religiosa, en municipio de provincia).

Para los discursos de familias que sí participan la no presencia de otras familias en el centro es una muestra ya no de desinterés pero sí de no poder hacerlo, y además, de no saber hacerlo.

\section{Mediación y articulación de alianzas}

En esta monofonía de argumentos sobre la participación de las familias en las escuelas y su significado en los mencionados contextos de desigualdad, encontramos un discurso que calificamos de mediador y que desde nuestro análisis se articula desde el enfoque del conflicto (López et al., 2005), emitido desde organizaciones sociales que trabajan como voluntariado en las actividades propuestas por los centros educativos.

En la mayoría de los casos se trata de organizaciones que trabajan en programas comunitarios para superar situaciones de exclusión y cuentan con un conocimiento profundo de las políticas que se han venido desarrollando en las ciudades y en barrios donde se ubican los colegios. Su análisis muestra una capacidad holística y reflexiva al reconocer la importancia de que familias y escuelas creen alianzas, de su valor para la mejora del rendimiento académico del alumnado, pero, a diferencia de otros posicionamientos como son el del déficit o la diferencia, en este caso, desde lo que hemos denominado enfoque del conflicto, identifican la escuela como espacio donde también se reproducen las desigualdades sociales (Delgado \& Stefanic, 2012).

Estos actores interaccionan con las familias desde ámbitos muy diversos (laboral, vivienda, salud, ayudas sociales, etc.), por lo que el escolar es considerado uno más en la problemática social que experimentan, pero desde luego no el único. Esa mirada global les lleva a considerar que un trabajo centrado exclusivamente en el rendimiento académico es restrictivo. En la entrevista grupal con voluntariado en la escuela C (Pública, laica, localizada en capital de provincia), recién inmersa en el proyecto de $\mathrm{CdA}$, les pedimos su valoración sobre las pretensiones de la escuela al fomentar la participación familiar y respondieron al respecto: "Es como que se basa demasiado en lo 
que saben a nivel académico ¿no?, y hay una serie de información que es importante (...) aquí no sólo se viene a aprender a leer y a escribir sino que aquí se aprenden muchas cosas, se aprenden valores..." (Entrevista grupal representante ONG, Escuela C).

Encontramos que para estos actores la conexión entre escuela y familias es importante porque lo consideran una estrategia de conocimiento y de reconocimiento mutuo, sobre todo para el caso del profesorado, permitiéndoles contextualizar las demandas sobre éxito escolar respecto al alumnado que acude a sus centros:

Los profesores también desconocen las vidas de esos niños, su realidad (...), muchos ahí se pierden, cuando les dicen los maestros a los niños: dejad..., o sea, en vuestro cuarto no tengáis el televisor puesto, claro, en los dormitorios no hay televisión, cuando hay niños que duermen en el salón de la casa, ¿̇no? (Entrevista grupal representante ONG, Escuela A Pública, laica, localizada en capital de provincia).

En este sentido, ellos sí se sienten expertos conocedores del barrio, de sus familias y las problemáticas que tienen; a su vez, se saben expertos también de los objetivos de la escuela, de sus estrategias, deseos y debilidades. Y desde aquí valoran de forma positiva el trabajo docente, sus dificultades y, también, el interés y esfuerzo de los maestros por transformar las escuelas y sus barrios.

Estos conocimientos definen, según los hallazgos de nuestro estudio, el papel de dichos agentes como mediadores entre el colegio y los contextos. Su posición "privilegiada" les permite el reconocimiento y la denuncia de lo que no se hace bien, de lo que sería necesario cambiar y mejorar a través de la acción socioeducativa tanto dentro como fuera de la escuela. Separación que queda representada física y metafóricamente con la existencia del muro tal como aludían en la entrevista grupal:

Yo creo que tradicionalmente hay un muro que es físico y que también se traslada a la realidad que no permite ese acceso de la comunidad y la familia a lo que pasa dentro de la escuela. No son partícipes de la educación, no son partícipes de la toma de decisiones, no son partícipes de muchas cosas (Entrevista grupal miembro de asociación Escuela C Pública, laica, localizada en capital de provincia).

Su conocimiento amplio del contexto y de la institución les permite adoptar un enfoque crítico hacia ambos lugares. Por un lado, consideran que el contexto de fuerte exclusión donde su ubican estos centros trae aparejado la estigmatización y también el conformismo sobre qué se puede cambiar y qué es inamovible y, por otro, a reivindicar el diálogo y alianzas entre escuelas y familias: 
En muchas ocasiones es que hay más miedo hacia las familias, ¿no?, porque como son más de exclusión pues ya se tienen muchos prejuicios (...) entonces cuanto menos se meta en la escuela, menos daño hace (Entrevista grupal miembro de asociación, Escuela D Pública, laica, localizada en capital de provincia).

Por tanto, consideran al diálogo como herramienta fundamental para repensar la reproducción de los discursos, dinámicas, procesos y representaciones entre ambos grupos, cuestionarlos y transformarlos (Feuerstein, 2000).

\section{Discusión}

Los resultados, en diálogo con estudios precedentes, revelan, en primer lugar, la existencia de discursos que legitiman posiciones más acordes a un determinado modelo de familia: aquel más cercano a las demandas de la escuela frente al que convierte en problema a aquellas que no armonizan con las demandas escolares. $\mathrm{Al}$ respecto, nuestros resultados coinciden con otras investigaciones en el ámbito internacional (Theodorou, 2007; Angus, 2009; Santillán y Cerletti, 2011) que muestran la existencia de discursos que, por un lado, definen la participación y caracterizan a las familias en función de ello como: familias cercanas a la "normalización" desde una perspectiva escolar-céntrica en donde se encontrarían aquellas familias que participan de lo que la escuela determina como positivo para el rendimiento escolar de los menores y desde el fomento de actitudes y hábitos que se asumen como beneficiosos para la promoción social tanto de las familias como de sus hijos/as, principalmente.

Por otro lado, encontramos en los discursos la ausencia de un cuestionamiento sobre las actividades que se diseñan para promover la participación, aunque ésta finalmente no se consiga (Feuerstein, 2000). Estos resultados indican que los discursos tanto del profesorado como de las familias que sí participan están supeditados a los enfoques del déficit y la diferencia.

Vinculado con lo anterior hallamos una representación que caracteriza a las familias como deficitarias y alejadas de la norma (por no responder a las demandas de presencia en el centro y acción académica en los hogares), ubicadas simbólicamente en terreno enemigo, que no se interesan, no participan y no comparten los dictados de lo que la institución escolar determina como provechoso para el éxito escolar.

De esta representación destaca la diferencia de las familias con la escuela en dos sentidos: bien por su privación social, dado que no cuentan con las condiciones materiales, disponibilidad de tiempo, recursos educativos o económicos para hacerlo; o bien, por su privación cultural, dado que no valoran 
el papel de la escuela y la cultura académica, lo cual evidenciaría sus escasas expectativas sobre sus hijos (discutido por Terrén y Carrasco, 2007; Carrasco et al., 2009; Franzé et al., 2010; Martín et al., 2014).

Ambos argumentos sirven para pensar a las familias por su déficit, a tenor de su (no) participación; e interpretamos ambos aspectos como manifestaciones evidentes de la relación entre desigualdades sociales y desigualdades escolares tal como las explica el sociólogo francés Dubet (2011) y que en nuestro caso se han hecho evidentes con familias de etnia gitana o inmigrantes extranjeras.

En el caso de estudio analizado, a pesar de sumergirse en procesos de transformación escolar, los centros educativos no logran el objetivo de obtener mayor participación de aquellas familias que ya de partida no participan, volviéndose a manifestar la tendencia a interpretar dichas relaciones desde el déficit y la diferencia. Resultados coincidentes con los encontrados por Domina (2005) y por Vincent et al. (2012) en las escuelas británicas cuando señalan la influencia de la intersección entre clase y etnia en los procesos de discriminación que experimentan las familias en las escuelas. De esta forma, trabajos como los de Carrasco et al. (2001) o Franzé et al. (2010) confrontan las conclusiones que responsabilizan a las familias por el fracaso en la participación, evidenciando en sus estudios cómo las familias inmigradas sí muestran gran interés por el papel socializador de la escuela, aunque no comparten la exigencia de adaptarse a sus modos y tiempos.

Por otro lado, nuestro trabajo revela además la existencia de un discurso mediador que situamos en el enfoque del conflicto procedente de las organizaciones intermediarias que trabajan con las escuelas de forma colaborativa y que revelan otras visiones sobre las familias más allá del déficit, como también se ha señalado en trabajos precedentes con poblaciones minorizadas (Río, 2010; Franzé et al., 2010; Baquedano-López et al., 2013; Antolínez, 2013).

Encontramos este discurso en actores y organizaciones de apoyo social a grupos marginales que conocen el contexto comunitario porque su labor se desarrolla tanto en el barrio como en los centros educativos con una proyección no sólo escolar sino social. El estudio de sus discursos revela la fragilidad de los enlaces entre ambos espacios -lo escolar, lo familiar o comunitario- y el interés por que lo comunitario y familiar imbrique en la escuela pero, también, para que la escuela se proyecte en lo comunitario.

Hallamos que las organizaciones intermedias, ajenas organizativamente a la escuela, facilitan lazos de relación entre escuela y familias, y nutren la co- 
municación y el diálogo colectivo entre ambos, resultados coincidentes con el análisis en profundidad realizado por López et al. (2005) en el contexto educativo de Estados Unidos o en España por Dietz y Rosón (2002), cuando analizan el papel de las ONGs con las administraciones públicas en el ámbito de trabajo de las migraciones.

\section{Conclusiones}

Los resultados expuestos y la discusión presentada indican que la participación de las familias en las escuelas se identifica en respuesta a las demandas académicas de la institución escolar, lo que a su vez reproduce las pautas de socialización legitimadas de las clases dominantes (Martín, 1998; Alonso, 2014). En segundo lugar, nuestro trabajo revela una forma de construir discursivamente la participación de las familias dual, siguiendo la línea de trabajos sobre participación escolar de López-Larrosa et al. (2010) o Simpkins et al. (2013): por un lado, las normalizadas, cumplidoras con los dictámenes de la norma escolar y presentes en la escuela; y por otro, las familias no presentes en el centro, conformistas con el bajo rendimiento de sus hijos e hijas y que no apoyan en el seno doméstico las tareas académicas desde aquí propuestas.

No obstante, creemos que estudios longitudinales sobre las experiencias en escuelas con proyectos para fortalecer las relaciones con familias y comunidad posibilitan una línea de investigación fructífera para interpretar si estas oportunidades de diálogo, en la medida que se dilatan en el tiempo y son nutridas por diversos actores, provocan desafíos hacia las posiciones y prácticas hegemónicas de la institución escolar. Creemos que a medio y largo plazo los diálogos con y junto a distintos actores, así como las resistencias que surjan, harán más proclives el cuestionamiento del modelo hegemónico de escuela.

Entendemos que experiencias como las aquí analizadas, en tanto en cuanto favorecen espacios de encuentro e interacción, tienen la oportunidad de provocar, a partir del conflicto, mayores y diversas condiciones para incorporar las intersecciones de etnia, clase e inmigración en el análisis de la participación tal y como abogan Baquedano-López et al. (2013) y, por tanto, poder así reconocer la desigualdad de distintos colectivos. Desigualdad que se evidencia en sus condiciones materiales de vida pero también en la invisibilización de sus discursos (Van Dijk, 1993) y la exclusión sistemática que provoca un sistema escolar que es per se barrera institucional para su presencia. El desafío educativo deriva entonces en aprovechar los procesos de reflexión y cambio escolar para revertir las dinámicas de exclusión en oportunidades de 
transformación colectiva desde lo que en este artículo hemos abordado como enfoque del conflicto.

Por otro lado, el reto para las políticas públicas obliga a contemplar la participación de manera no aislada o como asuntos que atañen casi exclusivamente a la institución escolar desde lo que ésta dictamine como norma para lograr el éxito académico y que, tal como ocurre en nuestro estudio en las escuelas analizadas, sirve de respuesta al por qué y para qué de la participación de las familias. Hacerlo de este modo asiste, como se evidencia en este trabajo y en precedentes, a que se sigan reproduciendo prácticas escolares estigmatizadoras hacia colectivos minorizados (Lott, 2001) y estas familias continúen siendo representadas desde las perspectivas del déficit o la diferencia (Banks, 2009).

Por el contrario, si deseamos una educación realmente para todos y todas, ésta ha de ir acompañada y coordinada con acciones políticas en materia social y económica que trasciendan las paredes del aula y la escuela. Como hemos mostrado en el caso de los discursos de las organizaciones sociales (López et al., 2005; Dietz y Rosón, 2002), la intervención socioeducativa que sale de lo meramente escolar para abordar la realidad cultural, social y económica de la comunidad en la que se inserta favorece una acción educativa dirigida no sólo hacia mejorar el rendimiento, sino sobre todo hacia la justicia social, desde el reconocimiento de las condiciones de desigualdad de vida de los y las menores con los que se trabaja, y la disolución, por tanto, de las barreras infranqueables entre familia y escuela.

\section{Bibliografía}

Alonso, Carlos (2014), "Familia, escuela y clase social: Sobre los efectos perversos de la implicación familiar", en Revista de la Asociación de Sociología de la Educación, año 7 , núm. 2, Madrid: Asociación de Sociología de la Educación.

Angus, Lawrence (2009), "Problematizing neighborhood renewal: community, school effectiveness and disadvantage", en Critical Studies in Education, año 50, núm. 1, Australia: Taylor \& Francis Group.

Antolínez, Inmaculada (2013), "La gestión de la diversidad cultural en España y México: construcción de la diferencia y exclusión en educación intercultural", en Revista Latinoamericana de Educación Inclusiva, año 7, núm. 2, Chile: Escuela de Educación Diferencial de la Facultad de Ciencias de la Educación de la Universidad Central de Chile.

Banks, James A. (2009), "Multicultural Education. Dimensions and paradigms", en Banks, James A. [ed.], The Routledge International Companion to Multicultural Education, New York y London: Routledge. 
María García Cano-Torrico, Inmaculada Antolínez-Domínguez y Esther Márquez-Lepe. Del déficit a la norma: representaciones sociales sobre familias y participación escolar

Baquedano-López, Patricia, Rebecca A. Alexander y Sera J. Hernández (2013), "Equity Issues in Parental and Community Involvement in Schools: What Teachers Educators Need to Know", en Review of Research in Education, año 37, Washington: American Educational Research Association.

Boethel, Martha (2003), Diversity: school, family y community connections. Anual synthesis 2003, SEDL: Austin, Texas.

Bourdieu, Pierre (1980), Le sens pratique, París: Les Éditions de Minuit.

Carrasco, Silvia, Jordi Pàmies y Marta Bertrán (2009), "Familias inmigrantes y escuela: desencuentros, estrategias y capital social”, en Revista Complutense de Educación, año 20, núm. 1, Madrid: Universidad Complutense de Madrid.

Charmaz, Kathy (2005), "Grounded theory in the 21st Century”, en Denzin, Norman K. \& Lincoln, Yyonna S. [eds.], The SAGE handbook of qualitative research, London: Sage Publication.

Colectivo IOÉ (2010), Posiciones y expectativas de las familias en relación al sistema educativo. Exploración cualitativa, Colección Estudios e Informes, Madrid: Ministerio de Educación.

Collet- Sabé, Jordi (2013), ¿Cómo y para qué educan las familias de hoy? Los nuevos procesos de socialización familiar, Barcelona: Icaria.

Comboni, Sonia y José Manuel Juárez (2001), "Educación y construcción de la identidad en contextos heterogéneos; el sentido de la educación indígena”, en Identidades. Revista de Educación y Cultura, año 2, núm. 5, abril-junio, Oaxaca: Instituto Estatal de Educación Pública.

Córdoba, Claudia (2011), "La concentración de alumnado extranjero en enseñanza Primaria: un estudio en dos ciudades andaluzas”, en RES. Revista española de Sociología, año 16, Madrid: Centro de Investigaciones Sociológicas.

Crozier, Gill (2001), “Excluded parents: The deracialisation of parental involvement”, en Race, Ethnicity and Education, año 4, núm. 4, London: Taylor y Francis Group.

Delgado, Richard y Jean Stefancic (2012), Critical Race Theory: an introduction, New York: New York University Press.

Díaz-Couder, Ernesto (1998), “Diversidad cultural y educación en Iberoamérica”, en Revista Iberoamericana de Educación. Monográfico: educación, lenguas, culturas, núm. 17, mayo-agosto, Organización de Estados Iberoamericanos (OEI).

Dietz, Gunther y Javier Rosón (2002), “¿Las organizaciones no-gubernamentales como intermediarios interculturales? Encuentros entre autóctonos e inmigrantes en ONG", en Serra, Luis [coord.], Inmigración extranjera en Andalucía, Sevilla: Junta de Andalucía.

Domina, Thurston (2005), "Leveling the home advantage. Assessing the Effectiveness of Parental Involvement in Elementary School”, en Sociology of Education, año 78, núm. 3, Pittsburgh: Sage Journals.

Dubet, Françoise (2011), Repensar la justicia social. Contra el mito de la igualdad de oportunidades, Buenos Aires: Siglo XXI.

Elboj, Carmen et al. (2002), Comunidades de aprendizaje. Transformar la educación, Barcelona: Graó. 
Epstein, Joyce L. (1995), “School/family/community partnerships: Caring for the children we share", en Phi Delta Kappan, año 76, núm. 9, Bloomington: Phi Delta Kappa International.

Feitó, Rafael (2014), “Treinta años de Consejos escolares. la participación de los padres y las madres en el control y la gestión de los centros sostenidos con fondos públicos", en Profesorado. Revista de currículum y formación del profesorado, año 18, núm. 2, Granada: Universidad de Granada.

Fernández-Enguita, Mariano (2014), "Ni es lo mismo, ni es igual... 40 años después", en Cuadernos de Pedagogía, núm. 451, Barcelona: Wolters Kluwer.

Feuerstein, Abe (2000), "School characteristics and parent involvement: Influences on participation in children's schools", en The Journal of Educational Research, año 94, núm. 1, London: Taylors \& Francis.

Flecha, Ramón (2009), "Cambio, inclusión y calidad en las Comunidades de Aprendizaje", en Cultura y Educación, año 21, núm. 2, Barcelona: Taylors \& Francis.

Forquín, Jean Claude (1983), "El enfoque sociológico del éxito y del fracaso escolares: desigualdades de éxito social y origen social”, en Educación y Sociedad, núm. 3, Madrid: Akal editores.

Frankenberg, Erica (2013), "The Role of Residential Segregation in Contemporary School Segregation", en Education and Urban Society, año 45, núm. 5, Pittsburgh: Sage Journals.

Franzé, Adela, M. Fernanda Moscoso y Albano Calvo (2010), "'Donde nunca hemos llegado". Alumnado de origen latinoamericano: entre la escuela y el mundo laboral", en Grupo Interdisciplinario de Investigador@s Migrantes [coord.], Familias, niños, niñas y jóvenes migrantes, Madrid: Iepala.

Freire, Paulo (1994), Cartas a quien pretende enseñar, Madrid: Siglo XXI.

Fullan, Michael (2001), The new meaning of educational change, New York: Teachers College Press.

Garreta, Jordi (2009), "Escuela y familias inmigradas: relaciones complejas", en Revista Complutense de Educación, año 20, núm. 2, Madrid: Universidad Complutense de Madrid.

Gatt, Suzanne, Mikko Ojala y Marta Soler (2011), "Promoting social inclusion counting with everyone: Learning Communities and INCLUD-ED", en International Studies in Sociology of Education, año 21, núm. 1, London: Taylor \& Francis Group.

Glasser, Barney y Anselm Strauss (1967), The Discovery of Grounded Theory: Strategies for Qualitative Research, Chicago: Aldine.

Jociles, Isabel y Adela Franzé [eds.] (2008), ¿Es la escuela el problema? Perspectivas socioantropológicas de etnología y educación, Madrid: Trotta.

Jodelet, Denise (2008), "El movimiento de retorno al sujeto y el enfoque de las representaciones sociales", en Cultura y representaciones sociales, año 3, núm. 5, México: Universidad Nacional Autónoma de México.

Laureau, Annette (2000), Home advantage: Social class and parental intervention in elementary education, New York: Falmer Press. 
María García Cano-Torrico, Inmaculada Antolínez-Domínguez y Esther Márquez-Lepe. Del déficit a la norma: representaciones sociales sobre familias y participación escolar

Lewis, Oscar (1961), Antropología de la pobreza, México: Fondo de Cultura Económica.

López, M. Elen, Holly Kredier y Julia Coffman (2005), "Intermediary organizations as capacity builders in family educational involvement", en Urban Education, año 40, núm. 1, Pittsburgh: Sage Journals.

López, Teresa [coord.] (2008), Familia, escuela y sociedad. Responsabilidades compartidas en la educación, Madrid, España. Ediciones Cinca.

López-Larrosa, Silvia y Marie Dubra (2010), "Las relaciones familia escuela desde la perspectiva de los adolescentes", en Revista Galego-Portuguesa de Psicoloxía e educación, año 18, núm. 2, A Coruña: Universidade da Coruña.

Lott, Bernice (2001), "Low income parents and the public schools", en Journal of Social Issues, año 57, núm. 2, London: Wiley.

Martín, Enrique (1998), “Los decires y los haceres”, en Papers: Revista de Sociología, núm. 56, Barcelona: Universitat Autónoma de Barcelona.

Martín, Eduardo, Manuel Río, Manuel y Pilar Carbajal (2014), "Prácticas de socialización y relaciones con la escolaridad de las familias más alejadas de la norma escolar”, en Revista de la Asociación de Sociología de la Educación, año 7, núm. 2, Madrid: Asociación de Sociología de la Educación.

Ogbu, John (1994), "From cultural differences to differences in cultural frame of reference", en Greenfield, Patricia M. y Cocking, Rodney, R. [coords.], Cross-cultural roots of minority child development, Hillsdale: Lawrence Erlbaum.

Ortiz, Elsa María (2013), "Las representaciones sociales: un marco teórico apropiado para abordar la investigación social educativa”, en Revista de Ciencias Sociales (Ve), año XIX, núm. 1, Venezuela: Redalyc.

Paniagua, Alejandro (2013), “Tan fuerte como su eslabón más débil. El caso de las AMPA en la integración escolar y social de las familias inmigradas”, en Revista Complutense de Educación, año 24, Madrid: Universidad Complutense de Madrid.

Paradise, Ruth (1994), "The autonomous behavior of indigenous students in classroom activities", en Álvarez, Amelia y Pablo del Río [coords.], Education as cultural construction, Madrid: Fundación Infancia y Aprendizaje.

Price-Mitchell, Marilyn (2009), "Boundary Dynamics: Implications for Building ParentSchool Partnerships", en The School Community Journal, año 19, núm. 2, Lincoln: Academic Development Institute.

Río, Manuel Ángel (2010), “No quieren, no saben, no pueden: categorizaciones sobre las familias más alejadas del campo escolar”, en Revista Española de Sociología (RES), año 14, Madrid: Federación Española de Sociología.

Santillán, Laura y Laura Cerletti (2011), "Familias y escuelas: repensando la relación desde el campo de la Antropología y la Educación”, en Boletín de Antropología y Educación, año 3, núm. 7, Buenos Aires: Universidad de Buenos Aires.

Simpkins, Sandra y Melissa Delgado (2013), "Socioeconomic Status, Ethnicity, Culture, and Immigration: Examining the Potential Mechanisms Underlying Mexican-Origin Adolescents' Organized Activity Participation”, en Developmental Psychology, año 49, núm. 4, Washington: American Psychological Association. 
Swap, Susan M. (1993), Developing home-school partnerships: From concepts to practice, New York: Teachers College Press.

Tannen, Deborah y James E. Alatis [eds.] (2001), Georgetown University roundtable on languages and linguistics, Washington: Georgetown University Press.

Terrén, Eduardo y Concepción Carrasco (2007), “Familia, escuela e inmigración”, en Migraciones, núm. 22, Madrid: Universidad Pontificia de Comillas.

Theodorou, Eleni (2007), "Reading between the lines: exploring the assumptions and implications of parental involvement", en International Journal about Parents in Education, año 1, Milano: ERNAPE.

Van Dijk, Teun (1993), Elite discourse and racism, Newbury Park, California: Sage Publications.

Van Voorhis, Frances, Michalle Maier, Joyce Epstein, Christana M. Lloyd (2013), The Impact of Family Involvement on the Education of Children Ages 3 to 8. Focus on Literacy and Math Achievement Outcomes and Social-Emotional Skills, New York: MDRC.

Vincent, Carol et al. (2012), "Intersectional work and precarious positionings: Black middle-class parents and their encounters with schools in England", en International Studies in Sociology of Education, año 22, núm. 3, London: Taylor \& Francis Group.

\section{Recursos electrónicos}

Eurostat (2013), "Basic Figures On the EU. Summer 2013 edition. Eurostat: European Commission”. Belgium: European Union. Disponible de: http://epp.eurostat. ec.europa.eu/portal/page/portal/europe_2020_indicators/headline_indicators [14 de julio 2013].

Ministerio de Educación, Cultura y Deporte (2012), Propuestas de mejora. Informe 2012 sobre el estado del sistema educativo, Madrid: Ministerio de Educación, Cultura y Deporte. Disponible en: https://sede.educacion.gob.es/publiventa/detalle.action?cod=15381 [22 de noviembre de 2013].

Ministerio de Educación, Cultura y Deporte (2013), Pisa 2012. Programa para la evaluación internacional de los alumnos. Informe español. Volumen I: Resultados y contexto, Madrid: Ministerio de Educación, Cultura y Deporte. Disponible en: http://www. mecd.gob.es/dctm/inee/internacional/pisa2012/actualizacion.13.3.2014/pisa2012informeespanol.pdf ?documentId=0901e72b818cf241 [21 de diciembre de 2013].

Organization for Economic Co-operation and Development (2012), Equity and Quality in Education: Supporting Disadvantaged Students and Schools. OECD Publishing, París: OECD. Disponible en: http://dx.doi.org/10.1787/9789264130852-en [1 de diciembre de 2013]. 


\section{Anexo}

\section{Tabla 1}

\section{Criterios de selección y características de las escuelas A, B, C, D, E y F}

\begin{tabular}{|c|c|c|c|c|c|}
\hline & $\begin{array}{l}\text { Contextos de } \\
\text { desigualdad }\end{array}$ & $\begin{array}{l}\text { Alumnado } \\
\text { minorizado }\end{array}$ & $\begin{array}{c}\text { Tamaño del } \\
\text { municipio }\end{array}$ & $\begin{array}{l}\text { Titularidad del } \\
\text { centro }\end{array}$ & $\begin{array}{l}\text { Estrategias } \\
\text { de apertura }\end{array}$ \\
\hline $\begin{array}{c}\text { Escuela } \\
\text { A }\end{array}$ & $\begin{array}{l}\text { Posee un ISC1: bajo, } \\
\text { dentro de las cinco } \\
\text { categorías establecidas } \\
\text { (Bajo, Medio-Bajo, } \\
\text { Medio, Medio-Alto, } \\
\text { Alto), por ello están } \\
\text { dentro del Plan de } \\
\text { Compensatoria2 }\end{array}$ & $\begin{array}{c}25 \% \text { de } \\
\text { alumnado } \\
\text { extranjero }\end{array}$ & $\begin{array}{c}\text { Está localizada } \\
\text { en capital de } \\
\text { provincia (más } \\
\text { de } 400.000 \\
\text { habitantes) }\end{array}$ & Pública & $\begin{array}{c}\text { Es } \\
\text { Comunidad } \\
\text { de } \\
\text { Aprendizaje }\end{array}$ \\
\hline $\begin{array}{l}\text { Escuela } \\
\text { B }\end{array}$ & $\begin{array}{l}\text { Posee un ISC bajo, } \\
\text { dentro de las cinco } \\
\text { categorías establecidas } \\
\text { (Bajo, Medio-Bajo, } \\
\text { Medio, Medio-Alto, } \\
\text { Alto), por ello están } \\
\text { dentro del Plan de } \\
\text { Compensatoria }\end{array}$ & $\begin{array}{c}\text { Cerca de } \\
\text { un } 65 \% \text { de } \\
\text { etnia gitana } \\
\text { nacional y } \\
25 \% \text { alumnado } \\
\text { extranjero }\end{array}$ & $\begin{array}{c}\text { La escuela B } \\
\text { está localizada } \\
\text { en municipio } \\
\text { de provincia } \\
\text { (entre } 50.000 \\
\text { y } 100.000 \\
\text { habitantes) }\end{array}$ & $\begin{array}{l}\text { Concertada } \\
\text { (titularidad } \\
\text { privada y } \\
\text { financiación } \\
\text { pública } \\
\text { mediante } \\
\text { subvenciones) }\end{array}$ & $\begin{array}{c}\text { Es } \\
\text { Comunidad } \\
\text { de } \\
\text { Aprendizaje }\end{array}$ \\
\hline $\begin{array}{c}\text { Escuela } \\
\text { C }\end{array}$ & $\begin{array}{l}\text { Posee un ISC bajo, } \\
\text { dentro de las cinco } \\
\text { categorías establecidas } \\
\text { (Bajo, Medio-Bajo, } \\
\text { Medio, Medio-Alto, } \\
\text { Alto), por ello están } \\
\text { dentro del Plan de } \\
\text { Compensatoria }\end{array}$ & $\begin{array}{c}26 \% \text { de } \\
\text { alumnado } \\
\text { extranjero y } \\
40 \% \text { de etnia } \\
\text { gitana nacional }\end{array}$ & $\begin{array}{c}\text { Está localizada } \\
\text { en capital de } \\
\text { provincia (más } \\
\text { de } 400.000 \\
\text { habitantes) }\end{array}$ & Pública & $\begin{array}{c}\text { Es } \\
\text { Comunidad } \\
\text { de } \\
\text { Aprendizaje }\end{array}$ \\
\hline $\begin{array}{c}\text { Escuela } \\
\text { D }\end{array}$ & $\begin{array}{l}\text { Posee un ISC bajo, } \\
\text { dentro de las cinco } \\
\text { categorías establecidas } \\
\text { (Bajo, Medio-Bajo, } \\
\text { Medio, Medio-Alto, } \\
\text { Alto), por ello están } \\
\text { dentro del Plan de } \\
\text { Compensatoria }\end{array}$ & $\begin{array}{c}90 \% \text { de } \\
\text { población } \\
\text { gitana } \\
\text { nacional y } \\
5 \% \text { población } \\
\text { extranjera }\end{array}$ & $\begin{array}{c}\text { Está localizada } \\
\text { en capital de } \\
\text { provincia (más } \\
\text { de } 300.000 \\
\text { habitantes) }\end{array}$ & Pública & $\begin{array}{c}\text { Es } \\
\text { Comunidad } \\
\text { de } \\
\text { Aprendizaje }\end{array}$ \\
\hline
\end{tabular}




\begin{tabular}{|c|c|c|c|c|c|}
\hline & $\begin{array}{c}\text { Contextos de } \\
\text { desigualdad }\end{array}$ & $\begin{array}{l}\text { Alumnado } \\
\text { minorizado }\end{array}$ & $\begin{array}{c}\text { Tamaño del } \\
\text { municipio }\end{array}$ & $\begin{array}{c}\text { Titularidad del } \\
\text { centro }\end{array}$ & $\begin{array}{l}\text { Estrategias } \\
\text { de apertura }\end{array}$ \\
\hline $\begin{array}{c}\text { Escuela } \\
\text { E }\end{array}$ & $\begin{array}{l}\text { Posee un ISC bajo, } \\
\text { dentro de las cinco } \\
\text { categorías establecidas } \\
\text { (Bajo, Medio-Bajo, } \\
\text { Medio, Medio-Alto, } \\
\text { Alto), por ello están } \\
\text { dentro del Plan de } \\
\text { Compensatoria }\end{array}$ & $\begin{array}{c}\text { Menos de } 5 \% \\
\text { alumnado } \\
\text { extranjero }\end{array}$ & $\begin{array}{l}\text { Está localizada } \\
\text { en municipios } \\
\text { de provincia } \\
\text { (entre } 25.000 \\
\text { y } 50.000 \\
\text { habitantes) }\end{array}$ & Pública & $\begin{array}{c}\text { Es } \\
\text { Comunidad } \\
\text { de } \\
\text { Aprendizaje }\end{array}$ \\
\hline $\begin{array}{c}\text { Escuela } \\
\text { F }\end{array}$ & $\begin{array}{l}\text { Posee un ISC bajo, } \\
\text { dentro de las cinco } \\
\text { categorías establecidas } \\
\text { (Bajo, Medio-Bajo, } \\
\text { Medio, Medio-Alto, } \\
\text { Alto), por ello están } \\
\text { dentro del Plan de } \\
\text { Compensatoria }\end{array}$ & $\begin{array}{c}90 \% \text { de } \\
\text { población } \\
\text { gitana nacional }\end{array}$ & $\begin{array}{c}\text { Está localizada } \\
\text { en municipios } \\
\text { de provincia } \\
\text { (entre } 25.000 \\
\text { y } 50.000 \\
\text { habitantes) }\end{array}$ & Pública & $\begin{array}{c}\text { Es } \\
\text { Comunidad } \\
\text { de } \\
\text { Aprendizaje }\end{array}$ \\
\hline
\end{tabular}

Fuente: Elaboración propia.

ISCI: Referido al estatus socioeconómico (ocupación de las madres y de los padres, y recursos con los que cuenta el hogar) y cultural (nivel educativo de las madres y de los padres, y número de libros en el domicilio familiar) de los centros en unos márgenes entre -2,16 a 1,49. Para el caso concreto se sitúa entre 2,16 a -0,47 (Agencia Andaluza de Evaluación Educativa, 2011). Disponible: http://www. juntadeandalucia.es/educacion/agaeve/c/document_library/get_file?uuid=738e1b71-8660-4745bdcc-46bd256a564c\&groupId=35690

Plan de Compensatoria: Decreto 167/2003 sobre ordenación de la atención educativa al alumnado con necesidades educativas especiales asociadas a condiciones sociales desfavorecidas a partir de los Planes de Compensatoria (BOJA núm. 118 del 23 de junio).

Etnia gitana nacional: Dado que no existen en España fuentes oficiales que registren la pertenencia étnica, los datos que aportamos se fundamentan en las estimaciones realizadas por los propios centros educativos. 
María García Cano-Torrico, Inmaculada Antolínez-Domínguez y Esther Márquez-Lepe. Del déficit a la norma: representaciones sociales sobre familias y participación escolar

\section{Tabla 2}

\section{Técnicas de producción de datos y perfil de los informantes}

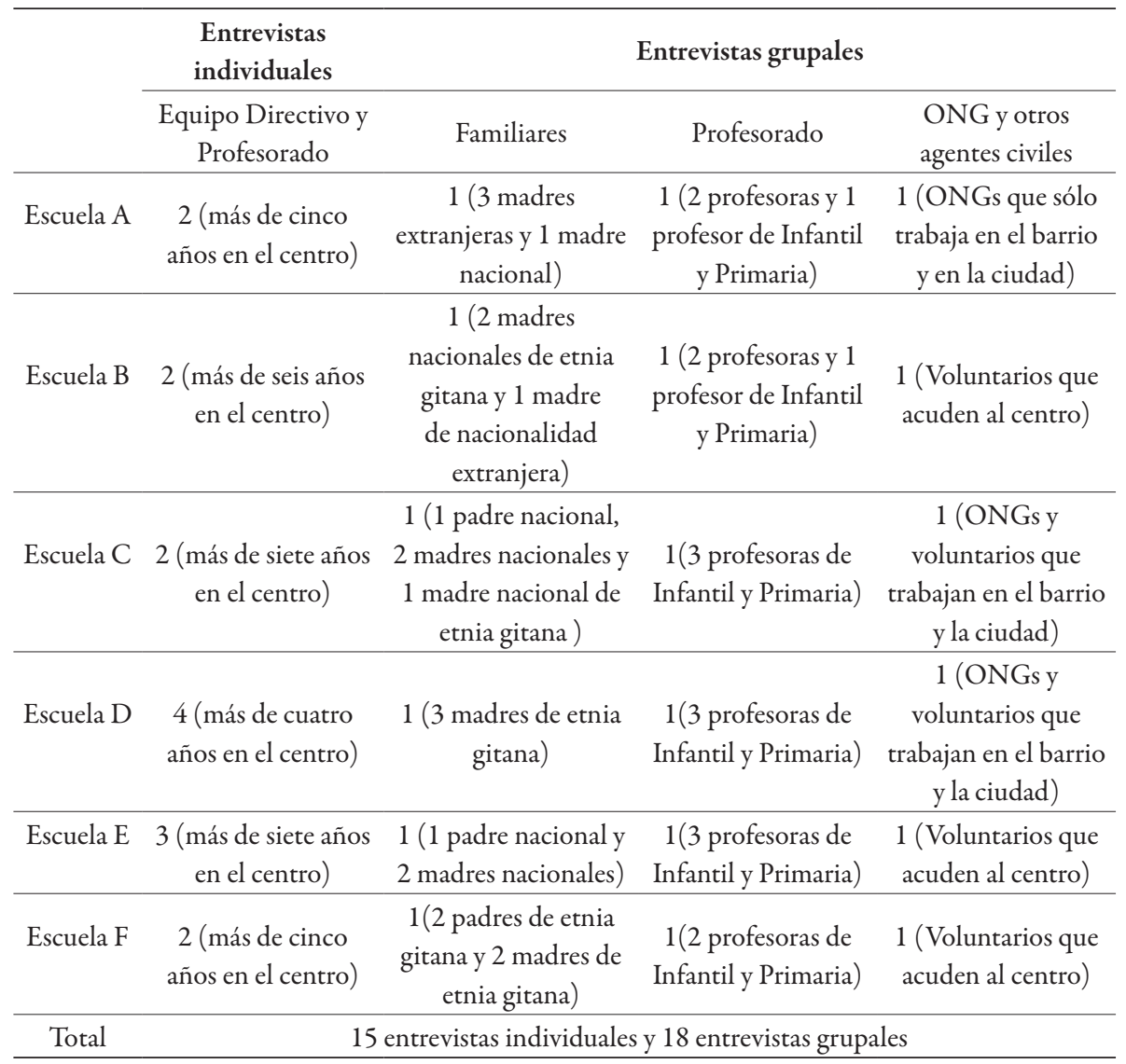

Fuente: Elaboración propia. 


\section{Tabla 3}

\section{Resumen información de entrevistas individuales}

\begin{tabular}{|c|c|c|c|c|}
\hline $\begin{array}{c}\text { Escuela/ Tipo de } \\
\text { escuela } \\
\end{array}$ & Sexo & Edad & $\begin{array}{c}\text { Trayectoria en el } \\
\text { centro }\end{array}$ & $\begin{array}{c}\text { Cargo o especialidad en el } \\
\text { centro }\end{array}$ \\
\hline \multirow{2}{*}{$\begin{array}{c}\text { Escuela A } \\
\text { (Pública, laica, } \\
\text { en capital de } \\
\text { provincia) }\end{array}$} & Mujer & 47 años & 20 años en el centro & $\begin{array}{c}\text { Directora Especialista en } \\
\text { Pedagogía Terapéutica }\end{array}$ \\
\hline & Mujer & 35 años & 15 años en el centro & $\begin{array}{l}\text { Jefa de estudio } \\
\text { Primarias }\end{array}$ \\
\hline \multirow{2}{*}{$\begin{array}{l}\text { Escuela B } \\
\text { (Concertada } \\
\text { Religiosa, } \\
\text { municipio de } \\
\text { provincia) }\end{array}$} & Mujer & 41 años & 21 años en el centro & $\begin{array}{c}\text { Directora Especialista en } \\
\text { Inglés }\end{array}$ \\
\hline & Hombre & 35 años & 8 años en el centro & $\begin{array}{c}\text { Especialista en Pedagogía } \\
\text { Terapéutica } \\
\text { Coordinador programa } \\
\text { Compensatoria }\end{array}$ \\
\hline \multirow{2}{*}{$\begin{array}{c}\text { Escuela C } \\
\text { (Pública, laica, } \\
\text { capital de } \\
\text { provincia) }\end{array}$} & Mujer & 47 años & 8 años en el centro & $\begin{array}{l}\text { Directora Profesora de } \\
\text { Educación Infantil }\end{array}$ \\
\hline & Mujer & 54 años & 9 años en el centro & $\begin{array}{c}\text { Jefa de estudios Especialista } \\
\text { de Pedagogía Terapéutica }\end{array}$ \\
\hline \multirow{4}{*}{$\begin{array}{c}\text { Escuela D } \\
\text { (Pública, laica, } \\
\text { capital de } \\
\text { provincia) }\end{array}$} & Mujer & 55 años & 20 años en el centro & $\begin{array}{c}\text { Directora Especialista en } \\
\text { Pedagogía Terapéutica }\end{array}$ \\
\hline & Mujer & 47 años & 15 años en el centro & $\begin{array}{c}\text { Jefa de Estudios } \\
\text { Primaria }\end{array}$ \\
\hline & Mujer & 42 años & 8 años en el centro & $\begin{array}{c}\text { Coordinadora del programa } \\
\text { Compensatoria }\end{array}$ \\
\hline & Mujer & 37 años & 6 años en el centro & Secretaria Primaria \\
\hline \multirow{3}{*}{$\begin{array}{c}\text { Escuela E } \\
\text { (Pública, laica, } \\
\text { municipio de } \\
\text { provincia) }\end{array}$} & Hombre & 45 años & 18 años en el centro & Director Primaria \\
\hline & Mujer & 50 años & 15 años en el centro & Jefa de estudios Primaria \\
\hline & Mujer & 44 años & 13 años en el centro & Secretaria Primaria \\
\hline \multirow{2}{*}{$\begin{array}{c}\text { Escuela } \mathrm{F} \\
\text { (Pública, laica, } \\
\text { municipio de } \\
\text { provincia) }\end{array}$} & Mujer & 45 años & 8 años en el centro & Directora Primaria \\
\hline & Mujer & 49 años & 4 años en el centro & Jefa de estudios Primaria \\
\hline
\end{tabular}

Fuente: Elaboración propia. 
María García Cano-Torrico, Inmaculada Antolínez-Domínguez y Esther Márquez-Lepe. Del déficit a la norma: representaciones sociales sobre familias y participación escolar

\section{Tabla 4}

\section{Resumen información de entrevistas grupales}

\begin{tabular}{|c|c|c|c|}
\hline $\begin{array}{l}\text { Escuela/ } \\
\text { Tipo de } \\
\text { escuela }\end{array}$ & Familias & Profesorado & ONG y otros agentes civiles \\
\hline $\begin{array}{l}\text { Escuela A } \\
\text { (Pública, } \\
\text { laica, en } \\
\text { capital de } \\
\text { provincia) }\end{array}$ & $\begin{array}{l}\text { 1: (23-10-2010) } \\
\text { - Madre nacionalidad } \\
\text { marroquí } \\
\text { - Madre nacionalidad } \\
\text { rumana } \\
\text { - Madre nacional }\end{array}$ & $\begin{array}{l}\text { 1: (16-03-2010) } \\
\text { - Tutora de Infantil } \\
\text { - Tutora de Primaria } \\
\text { - Tutor de Primaria }\end{array}$ & $\begin{array}{c}\text { 1: (30-03-2010) } \\
\text { - Voluntaria de centro } \\
\text { universitario } \\
\text { - Voluntario asociación } \\
\text { barrio } \\
\text { - Miembro ONG }\end{array}$ \\
\hline $\begin{array}{l}\text { Escuela B } \\
\text { (Concertada } \\
\text { Religiosa, } \\
\text { municipio de } \\
\text { provincia) }\end{array}$ & $\begin{array}{c}1 \text { (20-06-12): } \\
\text { - Madre nacional de etnia } \\
\text { gitana } \\
\text { - Madre nacional de etnia } \\
\text { gitana } \\
\text { - Madre nacionalidad } \\
\text { rumana }\end{array}$ & $\begin{array}{l}\text { 1 (28-11-12): } \\
\text { - Tutora de Infantil } \\
\text { - Tutora Primaria } \\
\text { - Tutor Primaria }\end{array}$ & $\begin{array}{c}\text { 1 (21-6-12): } \\
\text { - Voluntario antiguo alumno } \\
\text { del centro } \\
\text { - Voluntario maestro } \\
\text { jubilado } \\
\text { - Miembro de ONG barrio }\end{array}$ \\
\hline $\begin{array}{c}\text { Escuela C } \\
\text { (Pública, } \\
\text { laica, capital } \\
\text { de provincia) }\end{array}$ & $\begin{array}{c}1(14-6-12) \\
\text { - Padre nacional } \\
\text { - Madre nacional } \\
\text { - Madre nacional } \\
\text { - Madre nacional de etnia } \\
\text { gitana }\end{array}$ & $\begin{array}{l}\text { 1 (24-9-12): } \\
\text { - Tutora Infantil } \\
\text { - Tutora Primaria } \\
\text { - Tutora Primaria }\end{array}$ & $\begin{array}{c}\text { 1 (12-11-12): } \\
\text { - Técnica de Servicios } \\
\text { sociales } \\
\text { - Miembro de asociación de } \\
\text { barrio } \\
\text { - Voluntaria ONG barrio }\end{array}$ \\
\hline $\begin{array}{l}\text { Escuela D } \\
\text { (Pública, } \\
\text { laica, capital } \\
\text { de provincia) }\end{array}$ & $\begin{array}{c}1(18-10-11): \\
\text { - Madre nacional de etnia } \\
\text { gitana } \\
\text { - Madre nacional de etnia } \\
\text { gitana } \\
\text { - Madre nacional de etnia } \\
\text { gitana }\end{array}$ & $\begin{array}{c}\text { 1 (4-11-11): } \\
\text { - Tutora de Infantil } \\
\text { - Tutora de Primaria } \\
\text { - Tutora de Primaria }\end{array}$ & $\begin{array}{c}1(3-11-11): \\
\text { - Voluntaria ONG } \\
\text { - Miembro de ONG } \\
\text { - Voluntaria de ONG del } \\
\text { barrio }\end{array}$ \\
\hline $\begin{array}{l}\text { Escuela E } \\
\text { (Pública, } \\
\text { laica, } \\
\text { municipio de } \\
\text { provincia) }\end{array}$ & $\begin{array}{l}\text { 1(13-11-11): } \\
\text { - Padre nacional } \\
\text { - Madre nacional } \\
\text { - Madre nacional }\end{array}$ & $\begin{array}{l}\text { 1 (14-11-11): } \\
\text { - Tutora de Infantil } \\
\text { - Tutora de Infantil } \\
\text { - Tutora de Primaria }\end{array}$ & $\begin{array}{c}\text { 1 (14-11-11): } \\
\text { - Estudiante universitaria de } \\
\text { Educación, antigua alumna } \\
\text { del centro, voluntaria } \\
\text { - Estudiante universitaria de } \\
\text { Educación, voluntaria }\end{array}$ \\
\hline
\end{tabular}




\begin{tabular}{|c|c|c|c|}
\hline $\begin{array}{l}\text { Escuela/ } \\
\text { Tipo de } \\
\text { escuela }\end{array}$ & Familias & Profesorado & ONG y otros agentes civiles \\
\hline $\begin{array}{c}\text { Escuela F } \\
\text { (Pública, } \\
\text { laica, } \\
\text { municipio) }\end{array}$ & $\begin{array}{c}1(09-02-12): \\
\text { - Padre nacional de etnia } \\
\text { gitana } \\
\text { - Padre nacional de etnia } \\
\text { gitana } \\
\text { - Madre nacional de etnia } \\
\text { gitana } \\
\text { - Madre nacional de etnia } \\
\text { gitana }\end{array}$ & $\begin{array}{l}1(05-03-12): \\
\text { - Tutora de Infantil } \\
\text { - Tutora de Primaria }\end{array}$ & $\begin{array}{c}1(13-02-12): \\
\text { - Coordinadora ONG } \\
\text { - Coordinadora ONG } \\
\text { - Voluntaria biblioteca en el } \\
\text { centro } \\
\text { - Miembro Asociación de } \\
\text { gitanos del municipio }\end{array}$ \\
\hline
\end{tabular}

Fuente: Elaboración propia.

María García Cano Torrico. Doctora por la Universidad de Granada, profesora Titular del Departamento de Educación en la Universidad de Córdoba, España. Líneas de investigación: educación intercultural y escuela, migraciones y relaciones escuela-comunidad. Publicaciones recientes: (en colaboración), coautora de Diversidad cultural y eficacia en la escuela. Un repertorio de buenas prácticas en centros de educación obligatoria, España: Ministerio de Educación de España (2011); Educación Intercultural y Comunidades de Aprendizaje. Alianzas, compromisos y resistencias en el escenario escolar andaluz, La Catarata (2012); "Una Comunidad de Aprendizaje desde el enfoque intercultural: diálogos, emergencias y contradicciones en la práctica escolar", en Revista Educación XX1 (2015).

Inmaculada Antolínez Domínguez. Doctora por la Universidad Pablo de Olavide. Investigadora post-doctoral en la Universidad Pablo de Olavide (Departamento de Trabajo Social y Servicios Sociales). Líneas de investigación: educación intercultural, género y trata, migraciones y políticas públicas. Publicaciones recientes: "Contextualización del significado de la educación intercultural a través de una mirada comparativa: Estados Unidos, Europa y América Latina", en Papeles del CEIC (2011); "La gestión de la diversidad cultural en España y México: construcción de la diferencia y exclusión en educación intercultural", en Revista de Educación Inclusiva (2013); "Crisis of the welfare state: an analysis of the responses from social work", en colaboración, en Revista de Cercetare si Interventie Sociala (2015). 
Esther Márquez Lepe. Doctora por la Universidad de Granada. Profesora del Departamento de Sociología de la Universidad de Sevilla, España. Líneas de investigación: multiculturalismo, la ciudadanía, la educación intercultural y la atención a la diversidad en los espacios educativos desde una mirada cualitativa. Publicaciones recientes: "Estrategias bilingües e interculturales en familias transmigrantes", en Revista de Educación (2010); “El aprendizaje por proyectos en espacios virtuales", en RUSC (2014); "Condiciones de posibilidad y desarrollo para una educación intercultural crítica. Tres estudios de caso en el contexto andaluz", en Revista Española de Investigaciones Sociológicas (2014).

Recepción: 2 de octubre de 2014.

Aprobación: 18 de junio de 2015. 
